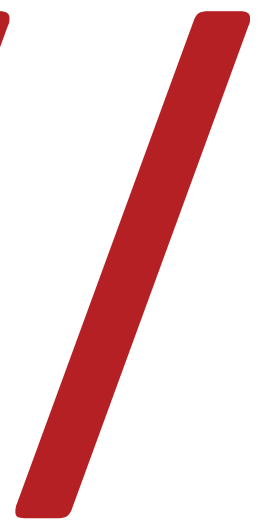

\title{
A hora dos fornos e 0 cinema político italiano por volta de $1968^{1}$ The hour of the furnaces and the Italian political cinema
}

\section{Mariano Mestman²}

\footnotetext{
${ }^{1}$ Artigo traduzido do italiano ao português por Fernando Seliprandy, doutor em História Social pela Universidade de São Paulo. Publicado originalmente em: Imago, Roma, n. 15, 2017, organizado por Ivelise Perniola e Luca Caminati (tradução do artigo em espanhol para o italiano de Riccardo Boglione).

${ }^{2}$ Agradeço a todas as pessoas entrevistadas. Também a Giovanni Spagnoletti e Pedro Armocida por terem me franqueado o acesso aos arquivos dos documentos inéditos da Mostra de Pesaro; a Claudio Olivieri e Antonio Medici pela cópia do registro de três minutos da Assembleia de Pesaro 68, conservada no Aamod; a Alberto Filippi pela cópia do filme I dannati della terra (Os condenados da terra).
} 
Resumo: a IV Mostra del Nuovo Cinema di Pesaro (Itália) foi um evento-chave no qual confluiu o cinema político latino-americano. Em junho de 1968, entre os festivais de Cannes (maio) e Veneza (agosto-setembro) - sacudidos pelas revoltas do 1968 -, Pesaro também viveu dias agitados, convulsionados. Foi aí que A hora dos fornos (1966-1968), de Solanas e Getino, teve sua estreia internacional. Este artigo reconstrói os eventos de Pesaro a partir de documentos internos da Mostra, além de escritos e testemunhos de seus principais protagonistas italianos: Lino Micciché, Goffredo Fofi, Valentino Orsini, entre outros. Ao mesmo tempo, o texto revisita os vínculos prévios de Solanas e Getino com o cinema político italiano, bem como a inserção de A hora dos fornos no circuito do cinema militante daquele país.

Palavras-chave: Mostra do Novo Cinema de Pesaro; 1968; A hora dos fornos, Terceiro Cinema; cinema político.

Abstract: the Pesaro Film Festival (Italy) was a key event where Latin American political cinema converged. In June 1968, between the Cannes (May) and Venice (AugustSeptember) festivals - both shaken by the 1968's riots -, Pesaro also lived turbulent and convulsed days. It was then The hour of the furnaces (1968), by Solanas and Getino, had its international premiere. This paper reconstructs the events of Pesaro based on internal documents of the festival, besides writings and testimonies of its main Italian protagonists: Lino Micciché, Goffredo Fofi, Valentino Orsini, among others. At the same time, this essay reviews the previous connections of Solanas and Getino to Italian political cinema, as well as the introduction of The hour of the furnaces within the circuit of militant cinema in that country.

Keywords: Pesaro Film Festival; 1968; The hour of the furnaces; Third Cinema; political film. 
Uma extensa bibliografia faz referência à influência do neorrealismo cinematográfico italiano sobre o chamado Novo Cinema Latino-Americano dos anos 1960. Entretanto, a realização de La hora de los hornos (A hora dos fornos, 1966-1968), de Fernando Solanas e Octavio Getino, é evidentemente um caso bem distinto, que provavelmente implica uma influência inversa - isto é, do cinema político latinoamericano sobre o europeu - ou pelo menos recíproca, na qual é patente um diálogo entre âmbitos políticos e cinematográficos 3 . Para o cinema latino-americano, os anos 1960 são um momento de renovação, quando se testemunha a formação de uma nova geração de jovens cineastas. Essa segunda geração (a de Glauber Rocha, Jorge Sanjinés, Miguel Littin, Fernando Solanas e tantos outros) experimentou novas linguagens e, em certos casos, recuperou uma tradição de montagem e de agitprop que estava distante das primeiras obras narrativas "realistas" dos neorrealistas italianos. Ela estava imbuída, antes, de demandas político-ideológicas de matiz terceiro-mundista, algo muito em voga naquele período. A hora dos fornos é um filme emblemático nesse sentido, seja por seu radicalismo ideológico ou por sua linguagem fílmica, a qual possui um amplo espectro de influências.

O filme argentino, com duração de mais de quatro horas, estrutura-se em três partes, cada uma se distinguindo por uma específica elaboração formal, por uma temática e por objetivos precisos. A primeira, "Neocolonialismo e violência” (90’), está concebida como um filme-ensaio no qual, ao longo de treze capítulos, o caráter neocolonial da dependência argentina e latino-americana é analisado. A segunda, “Ação para a liberação” (120’), subdivide-se em duas grandes partes: "Crônica do peronismo" e "Crônica da resistência". Pensada como um filme-ação e dedicada ao proletariado peronista, essa parte consiste, respectivamente, em uma análise dos dez anos do governo peronista (1946-1955) e em uma reconstrução do período subsequente de lutas, conhecido como "Resistência peronista" (1956-). A terceira parte, "Violência e liberação" (45’), propõe-se como um estudo sobre o significado da violência e sua força revolucionária.

Desde o início, diversos críticos sublinharam o modo como o filme, em particular a primeira parte, conseguiu articular uma linguagem original condizente com seu projeto revolucionário. Na realidade, na construção daquela linguagem, além da influência da experiência publicitária precedente de Solanas, A horas dos fornos empregava uma grande quantidade de meios e técnicas cinematográficas (sequências

${ }^{3}$ Escrevi sobre esses dois momentos das relações entre os cinemas italiano e latino-americano em Mestman, 2011. 
de noticiários, entrevistas e reportagens, material documental e reconstrução de cenas, fragmentos de outros filmes, fotos, cartelas, inserções gráficas, imagens congeladas, imagens publicitárias, efeitos de montagem, colagem), ao mesmo tempo que assimilava e reelaborava diversas influências cinematográficas ${ }^{4}$. Ataque direto ao espetáculo cinematográfico, em particular na sua versão hollywoodiana, a primeira parte inclui várias estratégias de combate à passividade do espectador, enquanto as partes sucessivas prosseguem com uma linha documentária mais clássica, embora exiba uma inovadora cadência reflexiva, que inclui testemunhos diretos e convida o espectador a refletir e extrair suas próprias conclusões para daí passar à ação. É com tal perspectiva que deve ser encarado o recurso aos estilemas do filme-ação, que influencia a própria estrutura do filme em diversos pontos. Por exemplo, na conclusão da "Crônica do peronismo", algumas palavras escritas na tela escura declaram "Espaço aberto ao diálogo", anunciando o momento em que o animador e o grupo militante, reunidos na projeção, devem organizar o debate, em um momento de excepcional intercâmbio com o público, para chegar à ação política. Voltaremos a esse ponto mais adiante.

Durante o próprio processo de realização do filme (1966-1968), os diretores começaram a incorporar um olhar para a classe operária peronista como sujeito fundamental da transformação revolucionária na Argentina, tal como ocorre com muitos intelectuais daqueles anos, os quais, influenciados pela chamada "esquerda nacional", uniram-se ao peronismo. Se a segunda parte da obra desenvolve essa linha, no seu todo o filme se inscreve em uma perspectiva político-ideológica que combina um "revisionismo historiográfico", os principais temas da "Tricontinental” de Havana e um terceiro-mundismo intransigente de tradição fanoniana. Contudo, embora este último aspecto estivesse em sintonia com uma parte importante da crítica e dos intelectuais italianos e europeus, a questão do peronismo e a figura de Perón não raro suscitaram reservas durante as apresentações internacionais do filme. Enquanto alguns entendiam esse ponto como expressão das "vias nacionais" (argentina, nesse caso) para se chegar à revolução, para outros ele era inaceitável, pois consideravam Perón próximo do fascismo europeu. Há exemplos desses posicionamentos políticos na Itália e no mundo.

\footnotetext{
${ }^{4}$ No que toca ao diálogo com o cinema italiano pós-neorrealista, por exemplo, vale lembrar o tratamento de alguns personagens da burguesia argentina em chave quase felliniana, ou os ecos da classe subproletária pasoliniana no retrato dos setores populares dos subúrbios de Buenos Aires. É evidente também a ligação crucial com La battaglia di Algeri (A batalha de Argel, 1966), de Gillo Pontecorvo, quanto ao discurso sobre o (neo)colonialismo e a violência revolucionária.
} 


\section{Antes da revolução de 1968}

Uma conexão entre o cinema político italiano e A hora dos fornos (em suas origens) teve inicialmente como protagonista o diretor italiano Valentino Orsini, alguém que, perto da metade dos anos 1960, contatou Fernando Solanas e Octavio Getino em Buenos Aires para que estes participassem de um projeto de filme ambientado na Argentina. O cineasta italiano encontrava-se na Argentina entre 1964 e 1965, dado que então realizava um documentário industrial, de encomenda, relativo ao gasoduto Pico Truncado-Buenos Aires, construído por uma empresa italiana para o Ente Nazionale Idrocarburi (ENI). Foi nessa ocasião que pôde conhecer o ambiente político e intelectual de Buenos Aires e convocar alguns jovens ligados ao cinema para realizar Los que mandan (Aqueles que mandam), um filme ambientado às vésperas de um golpe militar, do tipo que sucedia habitualmente na Argentina. Foi então que Solanas e Getino se encontraram pela primeira vez e, próximo ao fim de 1965, depois que o projeto foi recusado pelo Instituto de Cine Argentino, começaram as filmagens de A hora dos fornos.

Apesar do malogro do projeto de Los que mandan, dele resultou a publicação de um roteiro, lançado em setembro de 1965, assinado por Orsini, Solanas, Getino, o diretor Fernando Arce, além dos críticos Agustín Mahieu e Horacio Verbitsky (este último autor de uma entrevista com Orsini em 1964 em Buenos Aires) ${ }^{5}$. Naquela época, Orsini trabalhava na Itália com os irmãos Taviani nos filmes Un uomo da bruciare (Um homem a ser queimado, 1962) e I fuorilegge del matrimonio (Os fora da lei do casamento, 1963). Daí provém o interesse da entrevista pela história política (a resistência) e artística (teatral, cineclubista) do cineasta italiano. Na reportagem, Orsini define seu cinema com os Taviani como algo distante das tendências "irracionalistas" de Antonioni, Fellini ou Bergman, das "experimentações formais" de Godard e do cinema social de Francesco Rosi, acusado de "renuncia[r] à poesia" e à "fantasia criativa” e de carecer de "imaginação artística” (VERBITSKY, 1964, p. 3-4). Embora Orsini recupere aspectos de todas essas tendências (em particular a última), naquele contexto ele se declara a favor de um cinema simultaneamente realista e poético, assumindo "uma atitude crítica (voltada a temas e personagens), uma distância, uma ironia que impede a identificação” (VERBITSKY, 1964, p. 3-4). Trata-se, em certo sentido, da perspectiva que caracterizava Los que mandan. Anos depois, Orsini recordará aquele encontro com o grupo argentino:

$\overline{{ }^{5} \text { VERBITSKY, } 1964 .}$ 
A nossa relação era muito próxima. Mas aquele com quem eu tive uma relação realmente próxima foi Solanas. Porque eu sentia que Solanas tinha um verdadeiro temperamento para o cinema [...]. Naquele período, eu estava trabalhando para um consórcio que, na prática, tinha o contrato de construção do gasoduto. Mas eu tinha muito tempo livre e ficava por longos períodos em Buenos Aires. Com isso, claro, eu podia me dedicar às relações com eles. Na Itália, discutia-se muitíssimo o cinema político. E cinema político - particularmente como nós o discutíamos na Europa, ou melhor, ao menos nós das vanguardas europeias - significava um cinema político que colocasse também em discussão a linguagem cinematográfica. Que não desse atenção apenas à história, aos acontecimentos, mas também aos modos e códigos com os quais se narra $[\ldots]$. Então, na sequência dessas discussões, eu lancei a ideia de convidar o grupo para tentar fazer um filme de caráter político. E um filme que seria dividido em duas partes: uma primeira que devia ser uma análise do poder na Argentina, onde já se sentia no ar a presença de um golpe por parte dos militares; e uma segunda parte, que devia incluir os modos de reagir para contestar um evento desse tipo. Ou seja, era praticamente um filme-ensaio [...]. Havia um pré-roteiro da primeira parte, a segunda ainda precisava ser criada do zero, até porque era a mais difícil [...]. Eles é que faziam tudo. Eu discutia com eles e depois eles elaboravam a redação. (informação verbal).

Chama atenção que a historiografia quase não tenha mencionado esse vínculo precoce que está na origem do encontro entre Solanas e Getino e que durará até a estreia mundial do filme na Itália, na IV Mostra del Nuovo Cinema di Pesaro de 19687. Nesse sentido, o roteiro publicado de Los que mandan contém elementos recuperados mais tarde - ainda que indiretamente - em A horas dos fornos e I dannati della terra (Os condenados da terra, 1969), o filme de ficção de teor testemunhal que Orsini e Alberto Filippi estavam realizando nos mesmos anos. Às vésperas da Mostra de Pesaro, Orsini colocará os argentinos em contato com Giuliani De Negri, proprietário da Ager Film e produtor dos Taviani, para finalizar a edição de A hora dos fornos em Roma, entre abril e maio de 1968. Orsini e Filippi chegam a disponibilizar para os argentinos filmagens feitas anteriormente, rodadas nas zonas liberadas pela guerrilha do Partido Africano pela Independência da Guiné e de Cabo Verde, na Guiné-Bissau, a serem inseridas

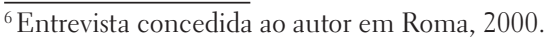

${ }^{7}$ A tal ponto que, no questionário que a Mostra solicita aos cineastas participantes, na pergunta sobre os autores estrangeiros que mais lhe interessavam, entre os europeus, Solanas só menciona Godard (algo óbvio) e Orsini ("o autor que mais contribui para uma problemática ideológico-revolucionária”, dizia Solanas). (SOLANAS, 1968, p. 5).
} 
na terceira parte do filme argentino. Em janeiro do ano seguinte, Solanas incluirá os italianos no projeto - no fim não concretizado - de um filme coletivo de título Por mucho Vietnam (Por muito Vietnã), o qual se propunha a "dar testemunho das novas forças revolucionárias hoje convergentes, desde a luta do Terceiro Mundo até à dos movimentos revolucionários europeus e estadunidenses", conforme explicita em carta endereçada a Alfredo Guevara em 10 de janeiro de 1969 (GUEVARA, 2008, p. 182).

Provavelmente a coisa mais interessante dessa relação entre os argentinos e Orsini seja o diálogo, inclusive em nível textual, entre A hora dos fornos e Os condenados da terra. Embora o filme italiano geralmente traga a data de 1969, a produção se inicia bem antes disso ${ }^{8}$. Sua montagem foi também finalizada na sede da Ager Film, quase simultaneamente à de A hora dos fornos e em uma moviola ao lado daquela usada pelos argentinos nas semanas precedentes a Pesaro 68. A sede da produtora de De Negri foi um espaço de encontro e convivência para os diretores italianos e argentinos. Mesmo que se trate de um documentário e de um filme de ficção, para usar uma distinção clássica, quando se observa com atenção, junto à ideologia terceiro-mundista, guevarista e fanoniana em comum ${ }^{9}$, ambos os filmes compartilham elementos ideológicos e formais: um uso semelhante dos intertítulos, de cartelas sobre a violência, de flashes sobre a tela escura, incluindo uma exortação à ação política do espectador, algo pouco usual àquela altura.

Naqueles anos, Orsini era um "comunista sem carteirinha": "Naturalmente eu não estava de acordo com as linhas políticas do partido", relembra (informação verbal $)^{10}$. Em certo sentido, assim como Filippi, ele aderia a uma nova esquerda mais terceiro-mundista do que operária e estudantil. Seguramente o seu conhecimento e seu interesse pelos grupos insurgentes latino-americanos se devem, em boa medida, à relação com Filippi, que havia iniciado sua militância na luta estudantil contra a ditadura do general Pérez Jiménez na Venezuela. Filippi, além disso, nos anos do trabalho coletivo, era representante da Frente de Liberação Nacional da Venezuela

\footnotetext{
${ }_{8}^{8}$ Uma primeira edição (parcial) do filme foi projetada a Alfredo Guevara, diretor do Icaic, em dezembro de 1967, às vésperas do célebre Congresso Cultural de Havana (Cuba). A estreia do filme completo na Itália ocorreu no contrafestival organizado como protesto contra o Festival de Veneza, em setembro de 1968.

\begin{abstract}
${ }^{9}$ Federica Colleoni escreveu um importante artigo sobre a influência de Fanon na obra de Orsini, em particular em Os condenados da terra (COLLEONI, 2014). Três meses depois de Pesaro 68, entrevistado por Cine al día (ARISTARCO, 1968), Aristarco referiu-se a Os condenados da terra como o "filme ideologicamente mais avançado entre os realizados na Itália nos últimos anos". Sua revista Cinema Nuovo - para além de algumas observações críticas - irá considerar A hora dos fornos como "o filme mais importante da Mostra de Pesaro" (CORBUCCI, 1968), dedicando-lhe depois outro longo artigo de Adelio Ferrero, no qual o filme é caracterizado como "uma grande lição de honestidade política e de correção socialista" (FERRERO, 1969).
\end{abstract}

${ }^{10}$ Entrevista concedida ao autor em Roma, 2000. 
na Europa, bem como dirigia, desde 1967, a seção latino-americana do Instituto para o Estudo da Sociedade Contemporânea, em Roma.

Contudo, Orsini repudiava a figura de Perón - legitimada, por sua vez, em A hora dos fornos -, ainda que reconhecesse a complexidade do peronismo e as forças operárias no interior desse movimento político. Por conseguinte, ele reivindicava o filme de Solanas e Getino como uma expressão político-cultural terceiro-mundista em sintonia com aquele momento histórico, e criticava a esquerda comunista internacional por sua falta de compreensão das singularidades do processo argentino e dos movimentos revolucionários do sul do mundo. Orsini relembra:

Era preciso explicar [na Itália] que o Partido Comunista Argentino tinha o pecado original de haver se posicionado contra Perón, razão pela qual havia perdido o contato com as massas; que o peronismo era feito de várias almas, que havia uma alma sinceramente sindicalista e de esquerda [...]. Aos poucos, essa ideia foi sendo aceita, e o foi sobretudo graças ao filme de Solanas. (informação verbal) ${ }^{11}$.

Nesse sentido, em um vasto texto de análise político-cultural das três partes do filme intitulado L'ora dei formi: appunti su una metodologia di cinema rivoluzionario nel Terzo Mondo, Alberto Filippi (1968) assinalou a complexidade ideológica, linguística e espetacular do filme. Definiu-o como um "manifesto, um programa de trabalho e um divisor de águas de extraordinária importância” (FILIPPI, 1968), referindo-se ao papel do intelectual na luta de liberação (tema-chave de Os condenados da terra e, como veremos, das discussões de Pesaro 68) e ao problema de como conceber a violência política e a violência cotidiana, a violência legal e a ilegal, a do opressor e a do oprimido, tanto na Argentina quanto no resto do Terceiro Mundo e na Europa. Além de detalhar os mecanismos linguístico-estilísticos do filme na construção de uma "pedagogia anticolonial", Filippi debruçava-se sobre a questão do peronismo como força operária, nacionalista e anti-imperialista. Mesmo fazendo ressalvas menores sobre a ausência, no filme, de certos esclarecimentos, o autor reconhecia a importância da crítica que a obra dirigia tanto ao papel histórico e contemporâneo do Partido Comunista Argentino, incluindo os demais partidos comunistas latino-americanos, quanto aos erros do peronismo. Filippi enfatizava não apenas estas últimas críticas, mas também o trabalho desenvolvido na segunda parte do filme por meio de cartas e entrevistas com dirigentes da Resistência peronista (iniciada depois da queda de Perón, em 1955), lido como

${ }^{11}$ Entrevista concedida ao autor em Roma, 2000. 
“recurso à memória popular cotidiana e coletiva" (FILIPPI, 1968) da classe operária, cujo objetivo era construir uma alternativa revolucionária naquele momento histórico ${ }^{12}$.

Trata-se de uma espécie de aceitação da proposta política do filme argentino, qual seja, a opção operária peronista articulada em chave fanoniano-guevarista, uma visão que, de distintos modos e com perspectivas diferentes, era compartilhada naqueles anos por diversos cineastas e críticos italianos. No entanto, houve quem questionasse abertamente a posição política do grupo Cine Liberación, bem como aqueles que ponderavam os limites da linguagem fílmica. Em um período de busca por uma linguagem "apropriada” para o cinema político-militante, Adriano Aprà e Gianni Menon (1969) realizaram uma longa entrevista com Orsini para Cinema e Film acerca de Os condenados da terra. Coerentemente com a linha da revista ${ }^{13}$, os entrevistadores começam apontando que Os condenados da terra "é um dos primeiros filmes em que a política é vista como um sujeito, e não como um objeto", um filme político, mas “sobre um indivíduo que tem entre seus problemas pessoais a política, que vive a política como dimensão subjetiva" (APRÀ; MENON, 1969). E, seguindo essa ótica, o fim da entrevista se volta para uma discussão entre os entrevistadores e Orsini sobre os limites de um filme como A hora dos fornos, o qual caracterizam como "unidimensional, assertivo, panfletário, com técnica publicitária”, considerando-o limitado, negativo, "nem mais nem menos que certos filmes populistas do neorrealismo italiano" (APRÀ; MENON, 1969). Diante de tais objeções, Orsini defende abertamente Solanas e o filme argentino, definindo-o como um filme “oportuno, preciso" (APRÀ; MENON, 1969) e declarando que os traços que, na Europa, podem ser lidos como “simplificações”, não o são na América do Sul. Orsini reabilita A hora dos fornos como "a primeira aproximação que um intelectual faz com a classe de forma direta, sem mediações”, e continua:

Solanas faz um discurso exclusivamente político, que é o tipo de abordagem mais imediata, mais legível, porque este é o tipo de discurso que o sindicato peronista, que o operário da fábrica quer escutar, porque não é forçado a enfrentar uma série de referências propostas, ao contrário, pelo espetáculo de [Glauber] Rocha. (APRÀ; MENON, 1969).

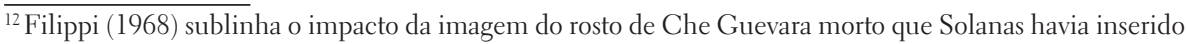
no final da primeira parte. Anos depois, ele escreveu um ensaio justamente sobre o mito do Che e a utopia guevarista, no qual recorda e discute a importância da figura e do pensamento de Guevara junto à esquerda europeia desde fins de 1967, retornando inclusive ao filme argentino (FILIPPI, 2007). Cf. também: Mestman, 2014.

${ }^{13}$ Gian Piero Brunetta (1998) caracterizou Cinema e Film como uma revista que "recusa programaticamente qualquer apoio de tipo historicista à obra, que olha com desconfiança as análises temáticas e privilegia o momento da fruição e da valorização do caráter cinematográfico dos procedimentos".
} 
Ainda que Orsini admirasse o Cinema Novo brasileiro e Glauber Rocha, aqui ele se referia à dimensão de intervenção política direta do filme de Solanas. De fato, essa contraposição entre Solanas e Glauber Rocha está presente em numerosos debates europeus daqueles anos sobre o cinema latino-americano ${ }^{14}$.

Antes dessa polêmica sobre o filme de Solanas, a revista Cinema e Film havia dedicado uma seção de seu número anterior, organizada por Adriano Aprà e Piero Spila, à análise da Mostra de Pesaro - sobre a qual voltaremos em breve (SPILA, 1968). Em seu texto, Spila havia atacado duramente A hora dos fornos, acusando o filme de representar um modelo equivocado de cinema político: "acúmulo de equívocos ideológicos e estéticos, internos e externos"; "um processo de autor que permanece arbitrário [porque] quando chantageia ideologicamente, comove emotivamente"; "uma hipótese de politização de uma realidade fílmica, emotiva e apriorística que, porém, falta ser racionalizada” (SPILA, 1968).

Pouco tempo depois, Solanas responderá, nas páginas da revista Ombre Rosse, com igual veemência: "Cinema e Film, a revista de Aprà, diz um monte de imbecilidades [...]. Eles têm o olhar da Via Veneto; de quatro casas romanas [...]. Se fizemos um esforço tão grande, não foi exatamente para figurar nas páginas de uma excelsa e pura revista europeia de cinema" (ARLORIO et al., 1969, p. 11) ) $^{15}$. Ao contrário, o objetivo de Solanas, assim como o impacto do filme, era político.

Essa resposta de Solanas está incluída em uma longa entrevista feita pela revista Ombre Rosse, originária de Turim e dirigida por Goffredo Fofi, alguém que naquele momento estava interessado no filme argentino e nas ideias de seu autor. Em um número prévio de Ombre Rosse, lançado depois da Mostra de Pesaro, Fofi começa seu artigo intitulado "Solanas e o cinema didático: muitos Vietnãs" com um elogio direto do filme, associado aos materiais que a própria revista e o movimento estudantil (movimento studentesco) haviam apresentado no referido festival (e sobre o qual logo retornaremos):

Análise e proposta, lê-se nos nossos documentos sobre o "cinema a serviço da revolução", e eis que surge, na grande

\footnotetext{
${ }^{14}$ Cinema e Film foi fundada por um grupo de jovens que rompeu com a Filmcritica. Em 1972, Filmcritica organizou uma mesa redonda com Renzo Rossellini (entre outros) na qual se repetirá uma contraposição similar. Rossellini afirmava que a realidade do Terceiro Mundo tinha necessidade de uma "expressão direta" que "documentasse a luta". Ciriaco Tiso (da equipe da revista), pelo contrário, questionava essa "espécie de fetichismo da câmera portátil", pois isso relegava o realizador/criador a um segundo plano. Também nesse caso, a contraposição principal se dava entre Solanas e Glauber Rocha ("contrainformação" versus "novas poéticas"). Tiso rejeitava, em A hora dos fornos, a centralidade da "visceralidade", da passionalidade e da irracionalidade, do sentimentalismo e, obviamente, a exaltação do peronismo, que "é puro fascismo", como afirmava (TISO, 1972).

${ }^{15} \mathrm{Um}$ estudo sobre ambas as revistas, com ensaios críticos e notas, é o de Volpi, Rossi e Chessa (2013).
} 
confusão de Pesaro, o primeiro filme político que sabe deixar de lado os dilemas estéticos para se valer de um método marxista de análise e proposta (busca ativa de uma objetividade revolucionária, a da luta de classes, contra todas as deformações e evasões burguesas). (FOFI, 1968, p. 10).

Depois de uma breve análise do filme - lido com precisão na dialética de suas três partes e em seu interesse pela classe operária peronista como protagonista da revolução na situação específica argentina e como "motor da mudança possível" (FOFI, 1968), seus limites e o apelo final à violência como força de liberação -, Fofi reconhece: "Em suma: é o filme teorizado por nós em nossos documentos, como método e como forma" (FOFI, 1968). E, a despeito de algumas reservas, de certas lacunas atribuíveis ao filme, o autor o reconhece como "nosso" e afirma:

coloca-se agora, cada vez com mais urgência, a necessidade de um cinema desse gênero também entre nós, ou melhor, de um filme que, como o faz A hora dos fornos para o "Terceiro Mundo", explique e proponha àqueles que deverão ser os protagonistas da revolução aqui, o mundo da sociedade do capitalismo complexo onde nós atuamos, e que busque com eles as vias revolucionárias necessárias e possíveis. (FOFI, 1968, p. 12).

Como se sabe, alguns anos depois, Goffredo Fofi se distanciará das derivas "leninistas" de 1968 e dos grupos sectários que proliferaram nos anos 197016. Chegado esse momento, ele tomará distância até mesmo do filme de Solanas:

Pino Solanas estava sempre por perto, eu o levei a alguns lugares, outros o levaram a outros, nós estávamos absolutamente entusiasmados com A hora dos fornos [...]. As pessoas se entusiasmavam por qualquer coisa que dissesse revolução, revolução, pois os estudantes eram muito burgueses e pequeno-burgueses, em suma, um ideologismo carregado. [O peronismo talvez] fosse considerado uma via nacional. Sim, e logo nos demos conta de que era uma outra fraude da história. [Mas, naqueles anos,] substancialmente, nós gostávamos dele.

\footnotetext{
16 “A primeira dúvida sobre os efeitos de 1968 surge então em mim da explosão da contestação dentro das categorias e escolas dos artistas, nas academias e nos festivais. O aspecto corporativo, as lutas de grupos e daqueles que 'ficaram de fora' contra os estabelecidos [...], a falta de escrúpulo com que certos presunçosos se reciclavam como revolucionários, isso me fez temer pelo que 1968 poderia ter desencadeado na nossa sociedade. Mais tarde vieram as lutas entre os novos partidecos, o culto ressuscitado da violência e a militarização progressiva das 'forças da ordem', e tudo isso enquanto novas parcelas da sociedade pareciam, ao contrário, ter aprendido alguma coisa com o 1968 dos estudantes, começando pelos operários." (FOFI, 1998, p. 10). Cf. também, do mesmo autor, o capítulo "Lontano dal cinema" (FOFI, 1999) e o capítulo "Cinema militante e cinema-verità" (FOFI, 1985).
} 
Eu escrevi uma crítica entusiasmada de A hora dos fornos, lembro-me que o Italo Calvino depois zombou de mim por uma semana. Eu tinha exagerado. (informação verbal) ${ }^{17}$.

\section{Pesaro, junho de 1968}

Os acontecimentos da Mostra de Pesaro de 1968 são bastante conhecidos, mas é importante voltar a eles por constituírem um cenário crucial, radical ainda que confuso, que explica a penetração do filme argentino na Itália e no mundo. Ao mesmo tempo, eles permitem introduzir na nossa história outro protagonista da conexão entre A hora dos fornos e o cinema político italiano: Lino Micciché, o diretor da Mostra.

Uma cena se repete nos relatos da estreia internacional de A hora dos fornos em Pesaro: os espectadores, depois da projeção da primeira parte, movidos por sua força expressiva, interpelados pelo rosto em primeiríssimo plano do cadáver de Che Guevara na tela, musicalmente realçado por um ritmo percussivo ensurdecedor, levantam-se gritando e carregam nos ombros o diretor do filme. Os testemunhos tendem a associar essa cena com a agitação de 1968 pelas ruas de Pesaro e a afluência dos espectadores para uma manifestação que terminou em confrontos com grupos fascistas e a polícia, com a prisão de militantes e cineastas. "Todo espectador é um covarde ou um traidor": esta frase de Frantz Fanon estava escrita em um cartaz afixado sob a tela durante a projeção. O filme se transformou em um ato político, como desejavam seus diretores a cada projeção, e tal como eles teorizariam pouco tempo depois com a ideia de filme-ação, característica do cinema militante - o qual, segundo eles, era a categoria mais avançada do Terceiro Cinema.

Alguns dias antes, o prestigioso Festival de Cannes fora ocupado por críticos, cineastas e estudantes, tendo sido encerrado sem premiações em 19 de maio, ao mesmo tempo que nascia em Paris os "Estados Gerais do Cinema Francês". Entre Cannes (maio) e Veneza (agosto-setembro), Pesaro (junho) se situava em uma posição especial. Naquele contexto, a direção da Mostra, com Micciché no comando, havia instituído a "autocontestação", proclamando que também os festivais se encontravam em uma crise histórica. Na abertura do evento, uma Assembleia Permanente decidiu rever a própria estrutura organizativa, ampliando seus critérios operativos no sentido de uma "autogestão" em colaboração com grupos culturais, artísticos e políticos, além

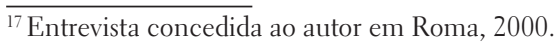


de estender as projeções para o circuito urbano e zonas operárias suburbanas, onde A hora dos fornos foi projetado, junto de outros filmes.

O crítico espanhol Fernando Lara publicou uma crônica exaustiva dos eventos de Pesaro, dia a dia. Lara mencionou a referida coincidência, em 4 de junho, entre uma manifestação política do 1968 no centro da cidade e a projeção da primeira parte de A hora dos fornos na Mostra, a poucos quarteirões de distância, e fez alusão inclusive às provocações dos grupos de extrema direita italianos contra os espectadores do festival: em resposta ao recrudescimento do ambiente causado pelas provocações neofascistas nos bares da cidade onde se reuniam os espectadores da Mostra, sobretudo na noite entre 6 e 7 de junho, a assembleia do festival decidiu, como "ato revolucionário", projetar novamente o filme argentino, na sessão vespertina, dessa vez na íntegra, com suas três partes. Lara escreve: "O filme se converteu na bandeira da competição, no ponto de referência de todos os encontros, de todos os comentários, desde que foi projetada sua primeira parte na terça-feira passada" (LARA, 1968). Similar protagonismo do filme argentino surge também nas recordações de Lino Micciché: "Solanas e Getino vieram aqui só por um mês para finalizar o filme, e depois seguiram para Pesaro, onde foram os protagonistas do debate" (informação verbal) ${ }^{18}$.

Por sua vez, Valentino Orsini e Goffredo Fofi foram duas das principais referências dessas agitadas jornadas, embora, em certo sentido, em posições opostas. Fofi e outros redatores de Ombre Rosse, junto dos ativistas do movimento estudantil, foram os que deram início à contestação anti-institucional. Vale a pena ler com atenção os documentos redigidos por eles, "Cultura a serviço da revolução" e "Centro-esquerda ampliada", de junho de 1968. Com posicionamentos radicais sobre a conjuntura, esses documentos criticavam duramente o sistema político dominante (da Democracia Cristã, mas também da oposição da "esquerda oficial”) por sua capacidade de neutralizar a intervenção dos intelectuais de esquerda, não apenas os relegando a uma zona especializada - isto é, a cultura, o cinema -, mas ainda ao lhes garantir um "ginásio para exercícios inofensivos que ofereçam a ilusão de uma pseudoautonomia, álibi subjetivo para sua efetiva integração”. É nessa linha que a Ombre Rosse e o movimento estudantil interpretavam criticamente a função do Festival de Pesaro e sua identidade de centro-esquerda, incluindo o papel de Micciché ("crítico oficial do PSU”): tudo fazia parte de uma política cultural baseada em uma série de "grandes mistificações". Entre elas, a reivindicação de

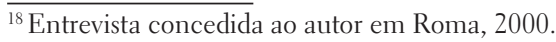


"liberdade cultural" encabeçada pela categoria dos intelectuais, a qual na verdade seria "claramente uma ilusão" na sociedade burguesa, alcançável apenas em uma sociedade "autenticamente socialista” (o que não era o caso da URSS). Seguindo essa linha de análise, a história de Pesaro, nas edições compreendidas entre 1965 e 1967, era criticada como uma "variante cultural da própria ideologia burguesa" na qual se verificava "a aplicação de análises puramente linguísticas ou de impulsos sentimentalistas mistificantes". Tal caracterização da história de Pesaro estendeu-se à adoção de uma posição contestatória também durante a edição de 1968.

O segundo documento, "Centro-esquerda ampliada", colocava em discussão a operação cultural da aliança entre críticos e cineastas presentes em Pesaro com o fim de cooptar e integrar o movimento que havia iniciado a contestação. A “autocontestação" proposta pelas próprias autoridades do festival era lida nessa chave. Frente a um movimento estudantil que "demonstrou ser, mais uma vez, a única força em condições de elaborar novas propostas e traduzi-las em ações”, no documento se afirmava que a "cultura de esquerda" (manifesta na Mostra de Pesaro) "não foi capaz de fazer qualquer tentativa de atualização efetiva" e "procurou manter a unidade a todo custo $[. .$.$] por temor de perder o papel de mediadora cultural de interesses$ burgueses e instrumento para o álibi coexistencial".

Em mais de uma ocasião, Fofi insistiu quanto ao alcance das posturas radicais de Ombre Rosse e do movimento estudantil contra críticos e cineastas pertencentes a uma esquerda socialista ou comunista - no fim das contas, "social-democrata", "oportunista" e "corporativista" - e sobre seus interesses no mundo do cinema (FOFI, 1971). Poucos dias depois do Festival, no número 35 de Quaderni Piacentini (julho de 1968), Fofi recuperou e comentou esses documentos (FOFI, 1977), desdobrando uma contraposição explícita entre a "cultura de esquerda” do PCI, da Associação Nacional Autores Cinematográficos (Anac) e dos outros grupos, detalhando ainda as ações dos grupos do movimento estudantil durante as jornadas de Pesaro e as razões de seu abandono final da assembleia em sinal de protesto contra as medidas que o festival e sua direção tinham em mente.

Sem renegar suas posições, em textos posteriores Fofi propôs releituras atenuadas daquelas jornadas, mas em todo caso críticas quanto aos partidos da esquerda tradicional italiana daqueles anos, incluindo seus cineastas. Anos depois, ele recordaria:

Em Pesaro, ocorreu a destruição, capitaneada por nós, então, a destruição do único festival de esquerda que existia na Europa. De um modo talvez irrefletido... isso nós 
compreendemos só depois. Mas um pouco sabíamos que era isso. Nós dizíamos: há o cinema do sistema, há o cinema da butique. (informação verbal) ${ }^{19}$.

Outros pontos de vista e recordações das jornadas de Pesaro apresentam perspectivas diferentes e trazem dados importantes sobre todas essas disputas. Mino Argentieri, por exemplo, fazia parte naqueles anos da comissão diretiva da Mostra e, desde 1964, era o responsável pela comissão de cinema do PCI. Logo, ele atuava no sentido oposto ao da "contestação" do movimento estudantil. Argentieri deu um detalhado testemunho sobre a revolta inicial e o acordo alcançado pela comissão diretiva da Mostra com uma parte dos manifestantes, no sentido de manter as projeções paralelamente à assembleia, bem como sobre a solicitação feita ao Partido Comunista de Roma para que dirigentes estudantis fiéis ao partido fossem infiltrados entre os manifestantes na assembleia de modo a acalmar os ânimos ${ }^{20}$.

No que toca ao lugar do filme argentino e, em geral, do cinema latinoamericano, é interessante observar que, no contexto da Mostra, Ombre Rosse e o movimento estudantil reconheciam "um único interlocutor válido: a delegação latinoamericana”, entendendo “a necessidade política [dessa delegação] de não romper totalmente com a 'cultura de esquerda burguesa' no atual momento". Não é casual, nesse sentido, a sintonia entre o documento "Cultura a serviço da revolução" e as ideias que Solanas levava consigo a Pesaro. De fato, o documento italiano citava dois parágrafos do texto de apresentação de A hora dos fornos em Pesaro (datado de maio de 1968, e certamente circulando em versão mimeografada naqueles dias) relativos à capacidade da cultura oficial, a cultura do sistema, de digerir e absorver qualquer crítica ou atividade que não servisse à luta de liberação nacional ${ }^{21}$. Outras partes do documento também dialogavam com as ideias de Solanas em Pesaro. Embora algumas delas fossem típicas da época, ainda assim é interessante observar temas comuns entre os textos do grupo Cine Liberación e os de Ombre Rosse e do movimento estudantil: o cinema como ato político; as intervenções cinematográficas possíveis "dentro" e "fora" do sistema; o cinema de agressão e de desmistificação; o cinema como expressão de um coletivo de militantes que intervém no processo revolucionário.

\footnotetext{
${ }^{19}$ Entrevista concedida ao autor em Roma, 2000.

${ }^{20}$ Conversa entre Argentieri e Antonio Medici (ARGENTIERI, 2001).

${ }^{21}$ Fofi (1977) também recuperava essa citação no artigo já mencionado de Quaderni Piacentini, no qual se referia a A hora dos formos como um "filme politicamente exemplar".
} 
Ao mesmo tempo, havia outros atores-chave da cena de Pesaro que estavam na órbita do filme argentino, justamente aqueles criticados por Ombre Rosse e pelo movimento estudantil, que tentavam negociar a não suspensão da Mostra, tais como Micciché ou Orsini. Nesse sentido, Orsini e Filippi faziam parte de um grupo de cineastas de esquerda que propunha converter o evento em uma "Mostra por um cinema livre e de oposição" disposta a confrontar a Mostra de Veneza, que ocorreria algumas semanas depois ${ }^{22}$.

Presidente da nova assembleia na qual a Mostra acabou se convertendo, preso na já aludida manifestação de rua, Orsini, junto de seu grupo e agregando os latino-americanos e as autoridades, conseguiu evitar que a Mostra fosse suspensa, como acontecera em Cannes. Pesaro era uma janela fundamental para a exibição dos filmes produzidos na América Latina e no mundo, coisa que o próprio movimento estudantil reconhecia, como já vimos. Solanas e os cineastas latino-americanos, compartilhando em princípio e se solidarizando com o espírito de protesto, não deixavam de pressionar as autoridades para que o evento, consideradas as modificações propostas, pudesse ainda assim ocorrer.

O artigo de Julio García Espinosa publicado em um número de Cine Cubano é eloquente quanto ao posicionamento dos cubanos e dos latino-americanos (ESPINOSA, 1968)23. Orsini, por sua vez, relembraria sua própria posição, em última instância, contrária à sabotagem do festival:

Em Pesaro havia uma grande confusão, um movimento estudantil que, naturalmente, queria abortar tudo, e nós conseguimos abortar esta sabotagem, demonstrando que o festival era importantíssimo para os amigos latino-americanos, era importante do ponto de vista político $[\ldots]$. O problema era Veneza, era Cannes, e não Pesaro. (informação verbal) ${ }^{24}$.

Bruno Torri, à época secretário-geral da Mostra, recorda:

Pode-se dizer que Pesaro, diferentemente de Veneza e de outras manifestações, não foi contestada de todo exatamente porque os cineastas latino-americanos - e havia tantos naquela ocasião - quiseram defender a mostra dizendo "não,

\footnotetext{
${ }^{22}$ Esse documento é assinado também por Pio Baldelli. Filippi e Baldelli dirigiriam mais tarde a revista Cinema e Rivoluzione (1970-1971). Em seu primeiro número, serão incluídos documentos do cinema latino-americano, como "Rumo a um Terceiro Cinema”, de Solanas e Getino.

${ }^{23}$ Cf. também a “Declaração do cinema latino-americano em Pesaro” (PESARO 68, 1968, p. 84).

${ }^{24}$ Entrevista concedida ao autor em Roma, 2000.
} 
esta é uma mostra de vanguarda, politicamente engajada, que para nós, cineastas latino-americanos, é muito importante. (informação verbal) ${ }^{25}$.

Torri relembra que, nos dias anteriores à abertura, a direção da Mostra se reunira em Roma com o cubano Julio García Espinosa e com Solanas, entre outros. O diretor argentino Fernando Birri, que então residia na capital italiana e era um habitual frequentador da Mostra, também se recorda de uma reunião na sua casa com Micciché e vários latino-americanos, às vésperas da abertura, organizada justamente para discutir a situação (informação verbal ${ }^{26}$. Em uma entrevista concedida a Micciché para a revista Cinema 60 em 1970, Solanas relembraria:

Eu vivi $[\ldots]$ aquela que foi a expressão mais forte da contestação nos festivais: a de Pesaro [...]. Foi bastante espontaneísta e confusa $[\ldots]$. Nós todos ficamos um pouco perplexos com uma contestação tão violenta e frontal contra um festival avançado como aquele [...]. O qual, repito, era o único, ou um dos pouquíssimos, a dar tanto espaço para as cinematografias mais avançadas; e que, particularmente no que diz respeito ao cinema latino-americano, havia demonstrado, por meio de seu Comitê Organizador, uma abertura, um interesse e uma predisposição que, até aquele momento, nenhum outro festival jamais havia tido. (MICCICHÉ, 1970, p. 19).

Pesaro 68 foi, então, um evento-chave para a recepção de A hora dos fornos em âmbito internacional, bem como para seu impulso em uma zona específica do chamado circuito alternativo.

\section{O circuito militante}

O filme argentino, sobretudo a primeira parte, a mais projetada, teve um forte impacto mesmo entre os cineastas da esquerda italiana, os quais, cada qual a seu modo, transitavam nas organizações - ou pelo menos em sua órbita - não apenas da nova esquerda, mas também da política cultural socialista ou comunista. A certa altura, o filme foi incluído no catálogo da Associação Recreativa e Cultural Italiana (Arci). Já em 1968, A hora dos formos aparece como referência explícita feita por Gianni Toti - de opção fílmico-política no diálogo entre cineastas e jovens militantes acerca das formas do novo cinema político no primeiro Cinegiornale libero

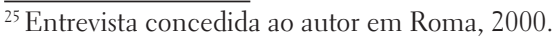

${ }^{26}$ Entrevista de Fernando Birri concedida ao autor em Roma, 2008.
} 
de Cesare Zavattini. Ao mesmo tempo, o filme foi celebrado por outros militantes atuantes no cinema, tais como Ugo Gregoretti e Ansano Giannarelli. Inclusive, em uma parte de Sierra Maestra, o filme de ficção de 1969 de Giannarelli realizado com Fernando Birri, este último, no papel de um guerrilheiro latino-americano, evocava explicitamente a frase "todo espectador é um covarde ou um traidor" de Frantz Fanon, remetendo à sua citação no filme de Solanas. Esse apelo ao espectador foi um dos elementos do filme mais destacados pela crítica italiana e mundial.

O objetivo era converter o espectador tradicional em ator do processo político pela via do debate, realizado durante ou depois da projeção, ao qual se seguiria a ação. Com efeito, em determinados pontos da segunda e terceira partes, o filme se interrompia e a voz over ou as legendas convidavam a um "diálogo" com os espectadores. Como já ficou dito, uma convocação similar do espectador está no final de Os condenados da terra, de Orsini e Filippi. Anos depois, Goffredo Fofi associará essas ideias sobre a "participação direta do espectador na criação prática do filme, a abolição da distância e da separação entre autor e espectador" com as teorizações posteriores acerca do videoteipe e das rádios livres que, nos anos 1970 e inícios dos 1980, proliferaram na Itália (FOFI, 1985, p. 215).

Na Mostra de Pesaro, Micciché programou a projeção de A hora dos fornos no circuito dos bairros populares articulado pelo festival. Fofi, por sua vez, acompanhou Solanas a Trento para a apresentação do filme na universidade ocupada pelos estudantes, além de outras universidades no norte da Itália (informação verbal) ${ }^{27}$. Em fevereiro de 1969, o influente Coletivo Cinema Militante (CCM) projetou todas as três partes do filme em Torino, com a presença do cineasta argentino. Houve projeções ainda na Perúgia e em Milão. Nos anos seguintes, um dos grupos que incluiu com frequência o filme em suas projeções foi o Centro Documentação Cinema e Luta de Classe, coordenado por Vico Codella. Esse grupo nascera de uma divisão interna do núcleo romano do Coletivo Cinema Militante e, por algum tempo, trabalhou em colaboração com a produtora San Diego Cinematográfica, de Renzo Rossellini ${ }^{28}$. Codella relembra que, entre os filmes estrangeiros que eram exibidos, A hora dos fornos era um dos mais projetados porque se prestava bem à organização

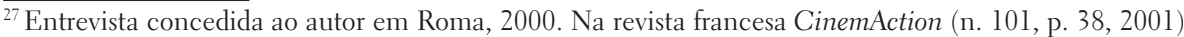
dedicada a Solanas, consta uma fotografia que o mostra durante aquela viagem junto de Fofi e do sociólogo Carlo Donolo, dos Quaderni Piacentini. Os três estão de pé em frente a um automóvel com as latas do filme empilhadas no asfalto.

${ }^{28}$ Além da atividade de produção, a San Diego distribuía alguns filmes. No caso de A hora dos fornos, tratava-se de uma versão de duas horas, síntese da primeira e segunda partes (informação verbal concedida ao autor por meio de entrevista com Rossellini em Roma, 2000).
} 
de debates (informação verbal) ${ }^{29}$. Por volta de 1971-1972, o Centro Documentação utilizava vários filmes italianos e estrangeiros para fazer trabalho político em diversas partes da Itália. Entre as cartas remanescentes trocadas entre seus organizadores e grupos de outros pontos do país, é possível encontrar referências a esse uso político recorrente do filme argentino:

Caro companheiro,

Na próxima semana providenciaremos o envio dos filmes solicitados em contato telefônico:

La hora de los hornos

Winter Soldier 71

Os filmes, como comunicado ao companheiro Pasquali, ficarão em posse do C.U.B. de Urbino por pelo menos duas semanas, para o programa de projeções previsto na Apúlia. Solicitamos, portanto: o programa das projeções, as localidades compreendidas e os debates políticos que se pensa fazer com os filmes $[\ldots]$.

Tenha em conta que o filme La hora... já foi fornecido pelo C.D. ao Círculo "La comune" da Apúlia e projetado em diversas localidades da região. [...]

Fico à espera das informações solicitadas, saudações comunistas. (CENTRO DOCUMENTAZIONE CINEMA E LOTTA DI CLASSE, 1971).

Desde sua estreia internacional em Pesaro, em 1968, A hora dos formos participou do debate sobre o cinema político mundial em outros festivais daqueles anos. O filme foi igualmente utilizado em chave militante não apenas por grupos políticos italianos, como vimos neste artigo, mas também por grupos de França, Espanha, GrãBretanha, Estados Unidos, Canadá, entre outros países do chamado Primeiro Mundo.

\section{Referências}

APRÀ, A; MENON, G. Valentino Orsini: I dannati della terra. Cinema e Film, Roma, n. 7-8, p. 58-69, 1969.

ARGENTIERI, M. Un grande disegno reformatori. In: MEDICI, A.; MORBIDELLI, M.; TAVIANI, E. Il Pci e il cinema tra cultura e propaganda. Roma: AAMOD, 2001.

$\overline{{ }^{29} \text { Entrevista de Vico Codella concedida ao autor em Roma, } 2000 .}$ 
ARISTARCO, G. Mirarse en un espejo o verse por dentro: entrevista con Guido Aristarco. Cine al día, Caracas, n. 6, p. 1823, 1968.

ARLORIO, P. et al. Fernando Solanas: il cinema come fucile. Ombre Rosse, Roma, v. 3, n. 7, p. 3-23, 1969.

BRUNETTA, G. P. Storia del cinema italiano: dal miracolo economico agli anni novanta. Roma: Editori Riuniti, 1998.

CENTRO DOCUMENTAZIONE CINEMA E LOTTA DI CLASSE. Carta do Centro Documentação Cinema e Luta de Classe. Roma, 9 fev. 1971. Arquivo Vico Codella.

COLLEONI, F. Fanon, violence and rebellion in italian cinema. Interventions, Abingdon, v. 17, n. 3, p. 329-342, 2014.

CORBUCCI, G. L'ora dei forni e l'autocontestazione. Cinema Nuovo, Roma, n. 194, 1968.

ESPINOSA, J. G. Pesaro y la nueva izquierda. Cine Cubano, Havana, n. 49-51, p. 85-92, 1968.

FERRERO, A. L'ora dei forni e il nostro terzo mondo. Cinema Nuovo, Roma, n. 202, 1969.

FILIPPI, A. L’ora dei forni: appunti su una metodologia di cinema rivoluzionario nel Terzo Mondo. Cinema 60, Roma, n. 69, 1968.

_. Il mito del Che. Torino: Einaudi, 2007.

_. Entrevista concedida a Mariano Mestman. Buenos Aires, 2017.

FOFI, G. Solanas e il cinema didattico: molti Vietnam. Ombre Rosse, Roma, n. 5, p. 10-15, 1968.

. Il cinema italiano, servi e padroni. Milano: Feltrinelli, 1971.

. Capire con il cinema. Milano: Feltrinelli, 1977.

. Cinema militante e cinema-verità. In: Dieci anni difficili. Firenze:

La casa Usher, 1985. Il '68 senza Lenin. Roma: Edizioni E/O, 1998.

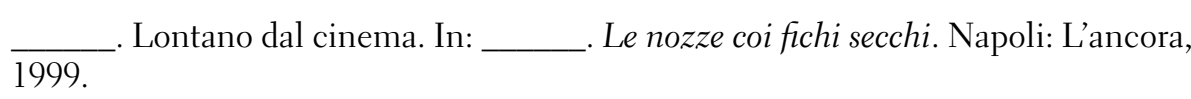
GUEVARA, A. ¿Y si fuera una huella? Epistolario. Madrid: Ediciones Autor, 2008. 
LARA, F. Pesaro, un festival violento y confuso, día tras día. Nuestro Cine, Madrid, n. 74, p. 29-37, 1968.

MESTMAN, M. From Italian Neorealism to new Latin American cinema: ruptures and continuities during the 1960s. In: GIOVACCHINI, S.; SKLAR, R. Global Neorealism 1930-1970: the transnational history of a film style. Jackson: University Press of Mississippi, 2011. p. 163-177.

A última imagem sacra da revolução latino-americana. Revista ECO-Pós, Rio de Janeiro, v. 17, n. 2, p. 1-17, 2014.

MICCICHÉ, L. Solanas: un cineasta militante. Cinema 60, Roma, n. 73-74, 1970.

PESARO 68. Dichiarazione del cinema latinoamericano a Pesaro. Pesaro: Arquivo da Mostra de Pesaro, 1968. Mimeografado.

SOLANAS, F. Resposta de Fernando Solanas ao Questionário da Mostra de Pesaro 68. Roma: Arquivo da Mostra de Pesaro, 1968. Mimeografado.

SPILA, P. Politicità del cinema e politicizzazione. Cinema e Film, Roma, n. 5-6, p. 41-52, 1968.

TISO, C. et al. Esperienze e ribellione a livello filmico: tavola rotonda su film d'informazione e film poetico/politici. Filmcritica, Roma, n. 222, p. 84-104, 1972.

VERBITSKY, H. Valentino Orsini y su fe en el hombre. Cine 64, Buenos Aires, v. 1, n. 7 , p. 3-4, 1964.

VOLPI, G.; ROSSI, A.; CHESSA, J. (Orgs.). Barricate di carta. Milano: Mimesis Cinema, 2013.

\section{Referências audiovisuais}

A HORA dos fornos. Fernando Solanas e Octavio Getino, Argentina, 1966-1968.

I DANNATI della Terra. Valentino Orsini, Itália, 1969.

LA BATTAGLIA di Algeri. Gillo Pontecorvo, Itália, 1966.

SIERRA maestra. Ansano Giannarelli, Itália, 1969.

submetido em: 6 abr. 2018 | aprovado em: 7 abr. 2018 